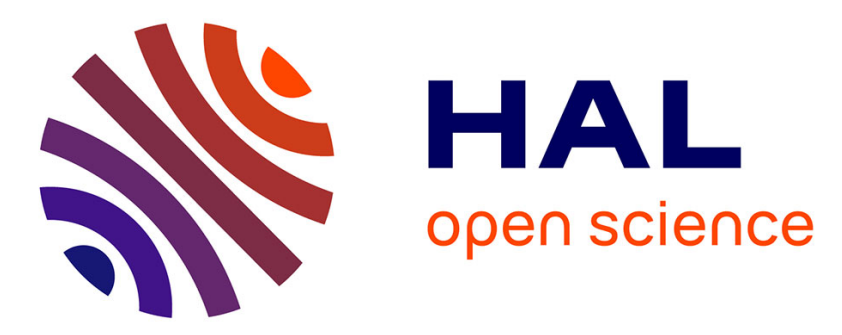

\title{
PEDOT:PSS/Fe2O3 as hybrid composite film for tuning color in electrochromism
}

\author{
Issam Mjejri, Aline Rougier
}

\section{To cite this version:}

Issam Mjejri, Aline Rougier. PEDOT:PSS/Fe2O3 as hybrid composite film for tuning color in electrochromism. 2019 E-MRS Spring Meeting Symposium R: Smart materials for green buildings and vehicles, E-MRS, May 2019, Nice, France. pp.2470-2473, 10.1016/j.matpr.2020.01.338 . hal-03054063

\section{HAL Id: hal-03054063 https://hal.science/hal-03054063}

Submitted on 11 Dec 2020

HAL is a multi-disciplinary open access archive for the deposit and dissemination of scientific research documents, whether they are published or not. The documents may come from teaching and research institutions in France or abroad, or from public or private research centers.
L'archive ouverte pluridisciplinaire HAL, est destinée au dépôt et à la diffusion de documents scientifiques de niveau recherche, publiés ou non, émanant des établissements d'enseignement et de recherche français ou étrangers, des laboratoires publics ou privés. 


\title{
PEDOT:PSS/ $\mathrm{Fe}_{2} \mathrm{O}_{3}$ as hybrid composite film for tuning colour in electrochromism
}

\author{
Issam MJEJRI and Aline ROUGIER
}

CNRS, Univ. Bx, Bx INP, ICMCB, UMR 5026, F-33600 Pessac, France

\begin{abstract}
Electrochromism is known as a modulation of the optical properties under an applied voltage. Among conductive polymers, poly(3,4-ethylenedioxythiophene):poly(styrene sulfonate) (PEDOT:PSS) switching from a neutral to reduced blue state, existing as commercial ink, allows to address displays applications. Aiming at enlarging the color panel, we recently developed an approach based on the addition of oxides leading to PEDOT-PSS+Oxides composites. Particularly, in this work, the influence of the incorporation of $\mathrm{Fe}_{2} \mathrm{O}_{3}$ on the electrochromic properties of the PEDOT:PSS based films deposited by bar coater are studied. The electrochemical and optical characterizations of the hybrid composite films PEDOT:PSS/Fe $\mathrm{O}_{3}$ by chronoamperometric (CA) coupled with in situ UV-visible spectroscopy, indicate that the hybrid composite film with $420 \mathrm{~nm}$ thickness shows a reversible switch from blue to red associated with a coloration efficiency of $\left(\mathrm{CE}=37 \mathrm{~cm}^{2} \mathrm{C}^{-1}\right)$ at $650 \mathrm{~nm}$ and transmittance modulation $(\Delta \mathrm{T}=22 \%)$ in lithium based electrolytes with switching speeds in the order of the sec. All these results suggest that the hybrid composite film, combining the benefit of mixing inorganic and organic materials, are promising materials for electrochromic devices.
\end{abstract}

Keywords: electrochromic materials; conductive polymers, $\mathrm{PEDOT}-\mathrm{PSS}, \mathrm{Fe}_{2} \mathrm{O}_{3}$, color tuning

\section{Introduction}

Electrochromism is generally defined as a reversible change of the optical properties upon applied voltage [1-3]. The combination of various materials both organic and inorganic in different device architectures, has opened up the variety of application areas for electrochromic materials aside to the long standing ones of rear view mirrors and smart windows [4-8]. Electrochromism is known to exist in various types of materials [9-12]. Among these, conducting organic polymers such as poly(3,4-ethylenedioxythiophene):poly(styrenesulfonate) (PEDOT:PSS) have received considerable attention owing to their greater durability, fast switching in redox states, environmental stability, improved processability, and color tunability through easy inks modification or formulation [13, 14]. Composites based on oxides and PEDOT:PSS mixtures can exhibit properties that are superior to those of the pure PEDOT and pure oxide. For instance, Cigdem Dulgerbaki et al [15] reported the synthesis of the hybrid electrochromic material PEDOT/ $\mathrm{WO}_{3}$, in which the tungsten addition leads to significantly enhanced durability under electrochemical cycling and improved coloration efficiency.

Recently, our group [16] has produced a serie of oxides and pigments-substituted PEDOT:PSS that are soluble in common organic solvents and therefore easily processable by doctor blading, serigraphy or bar coating. The electrochromic properties of these electroactive PEDOT:PSS can be adjusted by choosing the appropriate oxides of which nature will in particular play a role on the achieved color. For example we recently reported [17] that the electrochromic properties of PEDOT:PSS based devices were very sensitive to the addition of $\mathrm{Fe}_{2} \mathrm{O}_{3}$, switching in between a bluish to a reddish state. More precisely, the highest stability and color switching were achieved for small quantity of the $\mathrm{Fe}_{2} \mathrm{O}_{3}\left(2 \% \mathrm{Fe}_{2} \mathrm{O}_{3}\right)$. Aiming at further improvement, herein the influence of the thickness on the EC properties for single $2 \% \mathrm{Fe}_{2} \mathrm{O}_{3}$ PEDOT:PSS composite films, cycled in three electrodes cell, is discussed. 


\section{2. Experiment}

\subsection{Hybrid composite inks formulation}

The hybrid electrochromic inks were formulated from the mixture of the commercial PEDOT:PSS ink Agfa Orgacon EL-P5015 and commercial based $\mathrm{Fe}_{2} \mathrm{O}_{3}$ pigments (Rouge 110 purchased from Ocres de France, $\mathrm{Fe}_{2} \mathrm{O}_{3}$ content $>97.1 \%)$. The commercial PEDOT:PSS ink characterized by high-viscosity commercial paste $(>100,000$ $\mathrm{mPa} \cdot \mathrm{s}$ ) developed for screen printing was first homogenized with a three-roll mill and then diluted with ethanol to lower the viscosity. The various hybrid inks were prepared by mixing PEDOT:PSS, $\mathrm{Fe}_{2} \mathrm{O}_{3}$ and ethanol stirred for 15 $\mathrm{min}$ at room temperature, then dispersed using an ultrasonic bath for $30 \mathrm{~min}$ at room temperature. The $\mathrm{Fe}_{2} \mathrm{O}_{3}$ weight percentage was calculated from the PEDOT:PSS paste mass. Eight identical premixes were prepared: weight ratio of (PEDOT:PSS paste) $/\left(\mathrm{Fe}_{2} \mathrm{O}_{3}\right)=(100-\mathrm{x}) / \mathrm{x}$, with $\mathrm{x}=2 \%$. These preparations were then diluted with ethanol with a mixing ratio of $40 \mathrm{wt} \%$ of (PEDOT:PSS $+\mathrm{Fe}_{2} \mathrm{O}_{3}$ ) paste and $60 \mathrm{wt} \%$ of ethanol. The resulting dilute was dispersed using an ultrasonic bath for $15 \mathrm{~min}$ and then stirred again for $5 \mathrm{~h}$ at room temperature.

\subsection{Hybrid composite film deposition and characterization}

The films were deposited with a bar coater (K control from RK Print Coat Instruments, Erichsen) onto ITOcoated $\left(\mathrm{In}_{2} \mathrm{O}_{3}: \mathrm{Sn}\right.$ ) glass substrates (commercialized by SOLEMS with a resistance of $30 \Omega / \mathrm{sq}$ ) and then dried at 120 ${ }^{\circ} \mathrm{C} / 5$ min on a hot plate. The thickness of the (PEDOT:PSS/Fe $\mathrm{O}_{3}$ ) films, measured using a Dektak mechanical profilometer. The surface morphology was characterized by JEOL JSM-840 (operating at $15 \mathrm{kV}$ ) microscope.

\subsection{Electrochromic Measurements}

Electrochemical measurements of hybrid composite (PEDOT:PSS/Fe $\mathrm{O}_{3}$ ) films deposited on ITO/glass were carried out in a three electrodes cell configuration using a BioLogic SP50 potentiostat/ galvanostat apparatus. The counter electrode and reference electrode consisted of a platinum foil and saturated calomel electrode, $\mathrm{SCE}\left(\mathrm{E}_{\mathrm{SCE}}=\right.$ $0.234 \mathrm{~V} / \mathrm{ENH}$ ), respectively. The operating voltage was controlled between $-1 \mathrm{~V}$ and $+0.3 \mathrm{~V}$, in lithium-based electrolyte, namely, lithium bis-trifluoromethanesulfonimide (LiTFSI, Solvionic, purity N 99.99\%) in 1-etyl-3 methylimidazoliumbis(trifluoromethanesulfonyl)-imide (EMITFSI, purity $\mathrm{N} \mathrm{99.99 \% ).} \mathrm{All} \mathrm{the} \mathrm{electrochemical}$ measurements were performed at room temperature. The in-situ optical transmittance of PEDOT:PSS/ $/ \mathrm{Fe}_{2} \mathrm{O}_{3}$ hybrid composite films was measured using a Varian Cary 5000 UV-vis-NIR spectrophotometer between 300 and $750 \mathrm{~nm}$. Colorimetry analysis was carried out using a Konica Minolta CM-700D spectrophotometer, allowing the direct determination of colorimetric parameters of the CIE $(\mathrm{L} * \mathrm{a} * \mathrm{~b} *)$ color space.

\section{Results and Discussion}

To optimize the electrochromic performance of the hybrid composite film based 98\% PEDOT:PSS+ $2 \% \mathrm{Fe}_{2} \mathrm{O}_{3}$, on which composition has been earlier optimized [13], the thickness of the film was tuned in between $100 \mathrm{~nm}$ to over $1 \mu \mathrm{m}$ using a set of eight bars. Figure 1 shows the photographs of the various as-deposited films by bar coater, and in the reduced $(-1.0 \mathrm{~V})$ and oxidized $(+0.3 \mathrm{~V})$ states as detailed below. An increase in thickness is associated with a significant color change. The pronounced color gradient is supported by the corresponding measured $\mathrm{L}^{*} \mathrm{a} * \mathrm{~b}^{*}$ parameters mentioned beside each picture. The addition of $2 \mathrm{wt} \%$ of $\mathrm{Fe}_{2} \mathrm{O}_{3}$, that remains a low percentage, has a drastic effect on the color of as deposited state evolving from a blue (PEDOT-PSS) to a reddish (PEDOT:PSS+ 2\% $\mathrm{Fe}_{2} \mathrm{O}_{3}$ ) appearance. From a light reddish color for the $133 \mathrm{~nm}$ as-deposited film to a dark-black color for the thickest film $(1266 \mathrm{~nm})$ while the composite films adopt a red color in between $(420 \mathrm{~nm})$.

When cycled in lithium electrolyte using a three-electrode cells, an optical contrast from blue (-1 V) to reddishpink $(+0.3 \mathrm{~V})$, is visible for thickness below $420 \mathrm{~nm}$ while thicker films exhibit limited contrast due to rather dark reddish to black appearance. 


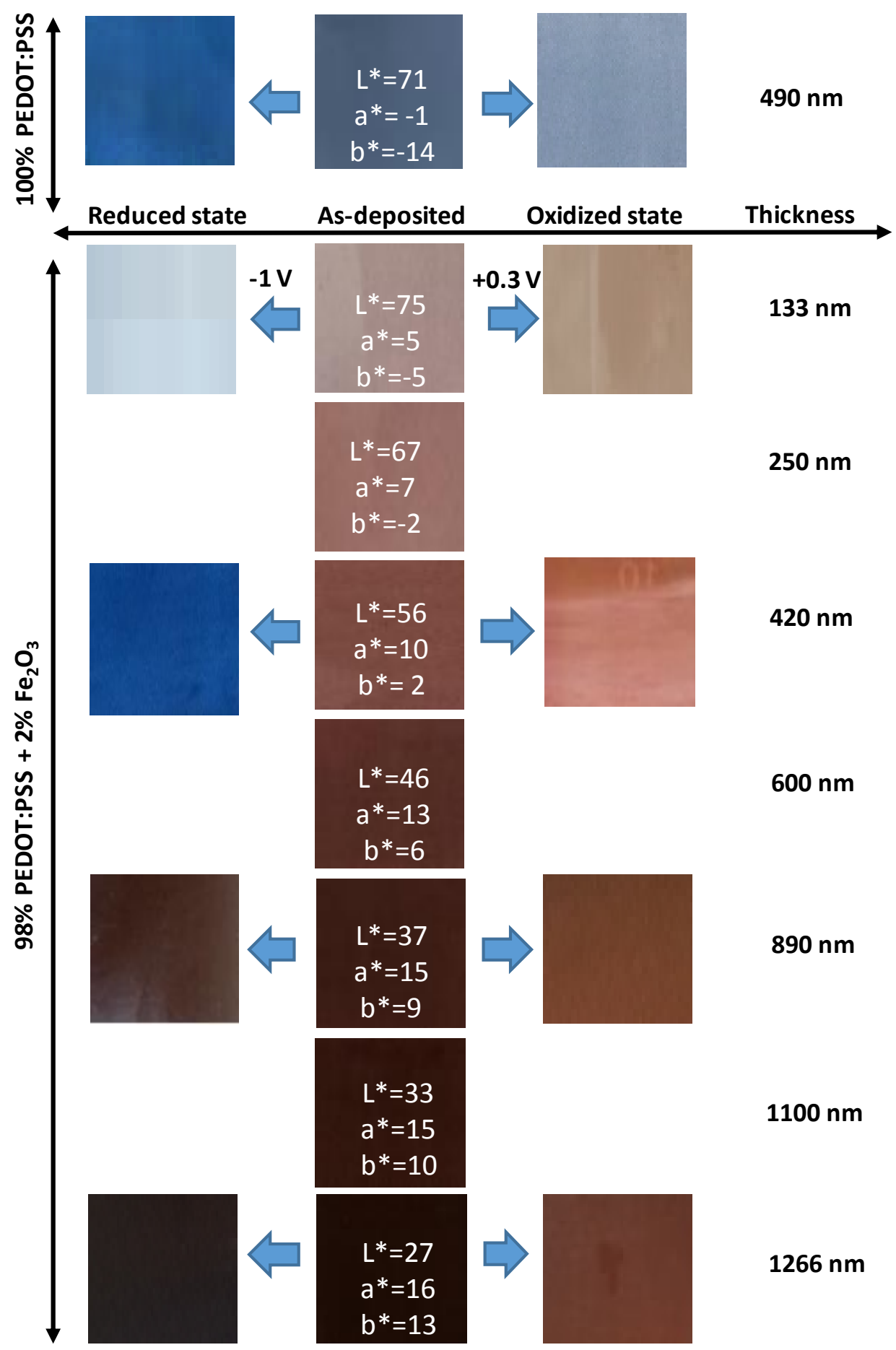

Figure 1. Photographs of the hybrid composite films (98\% PEDOT:PSS $+2 \% \mathrm{Fe}_{2} \mathrm{O}_{3}$ ) with different thicknesses and corresponding visual appearance of films in the reduced $(-1 \mathrm{~V})$ and oxidized $(+0.3 \mathrm{~V})$ states.

In CIE colorimetric space, the color is represented by three parameters, the luminance axis ( $\mathrm{L}^{*}$ ) and two hue axes $\left(a^{*}\right)$ and $\left(b^{*}\right)$, which can be used to define and compare quantitatively the colors. The evolution of the relative luminance $\left(\mathrm{L}^{*}\right)$, the hue $\left(\mathrm{a}^{*}\right)$ and $\left(\mathrm{b}^{*}\right)$ values of all hybrid composite films with different thicknesses were measured. Figure 2 shows the evolution of the $\mathrm{L}^{*} \mathrm{a} * \mathrm{~b} *$ parameters by adjusting thickness. L* luminosity parameter gradually decreases versus the thickness from 75 for $133 \mathrm{~nm}$ to 25 for the $1450 \mathrm{~nm}$ (this thickness is not displayed in Figure 2 
as the visible appearance looks alike the one of $1266 \mathrm{~nm}$ film) (Figure 2a). The hue color, which is directly characterized by the $\mathrm{a}^{*}$ and $\mathrm{b}^{*}$ values shows a saturation maximum around $1200 \mathrm{~nm}$ (Figure $2 \mathbf{b}$ and c). The Chroma of the color $\mathrm{C}^{*}$ was calculated by the following equation:

$$
\mathrm{C}^{*}=\left(\mathrm{a}^{* 2}+\mathrm{b}^{* 2}\right)^{1 / 2}
$$

The increase of the thickness from $133 \mathrm{~nm}$ to $1450 \mathrm{~nm}$ increases the $C^{*}$ value from 7 to 19 .
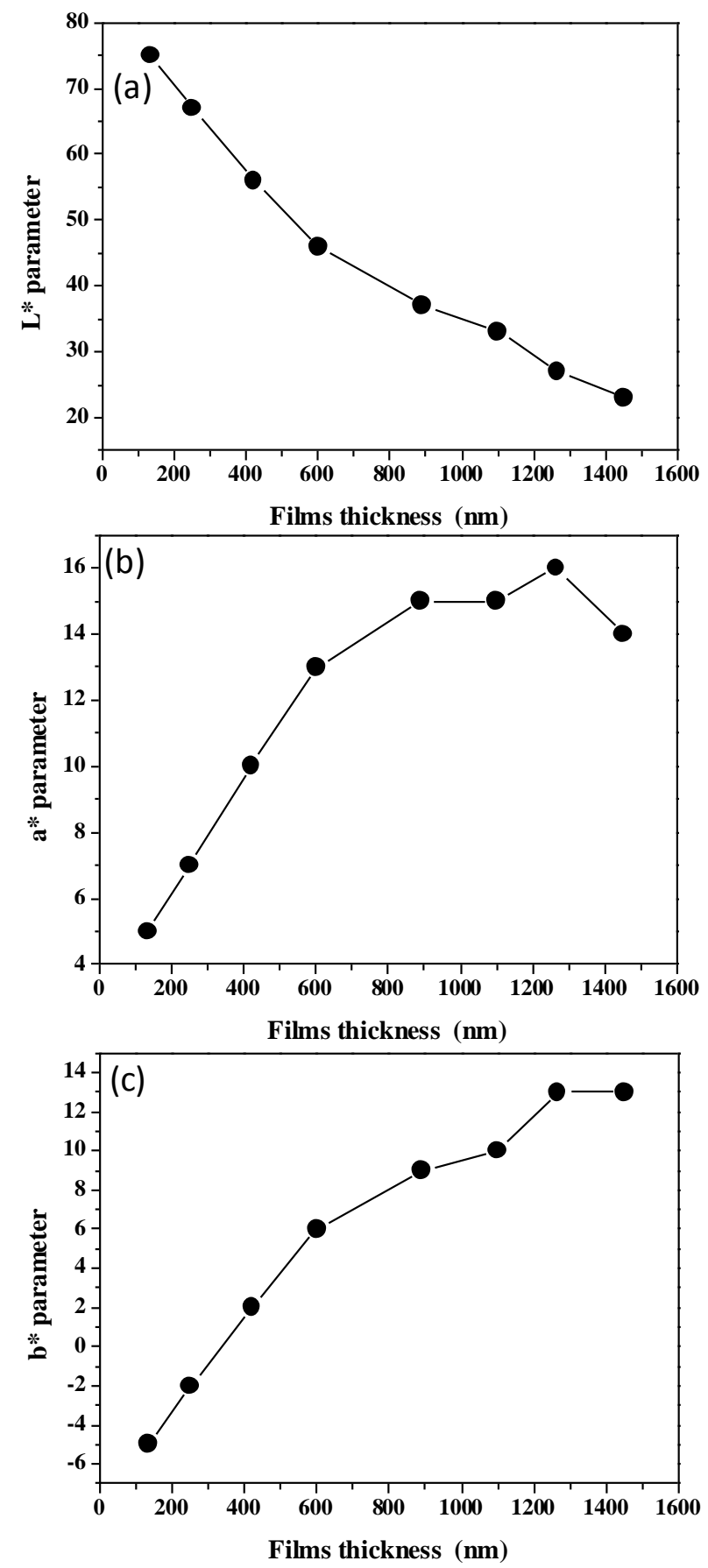

Figure 2. Evolution of the $\mathrm{L} * \mathrm{a} * \mathrm{~b} *$ parameters of $98 \%$ PEDOT:PSS $+2 \% \mathrm{Fe}_{2} \mathrm{O}_{3}$ films with different thickness. 
According to the electrochromic performance of the different films with different thickness, it can be concluded that the most visible optical contrast in between red to blue, instead of light blue to dark blue for pure PEDOT:PSS film, is observed for a thickness of $420 \mathrm{~nm}$. Thus in the following, we focus our attention on the hybrid composite film with $420 \mathrm{~nm}$ thickness.

The SEM analysis of the different films before and after $\mathrm{Fe}_{2} \mathrm{O}_{3}$ addition (Figure 3) demonstrates that the films morphology is quite different. Indeed, the PEDOT:PSS film appears homogenous with smooth surface (Figure 3a) while a homogenous dispersion of the $\mathrm{Fe}_{2} \mathrm{O}_{3}$ particles in the PEDOT:PSS matrix is visible for the PEDOT:PSS/Fe $\mathrm{O}_{3}$ (Figure 3b).
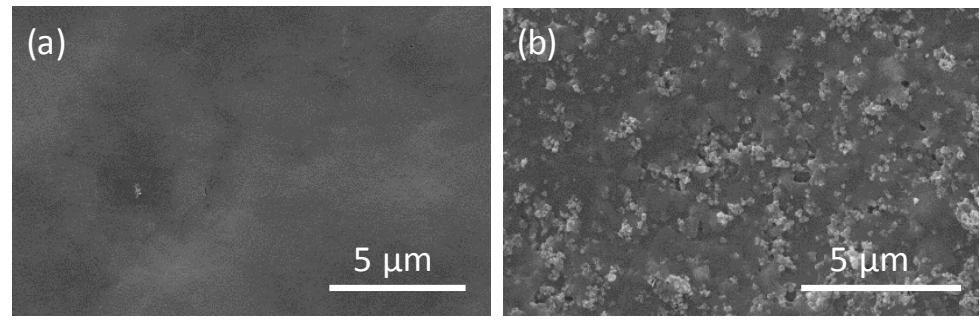

Figure 3. SEM images of the surface morphology of (a) PEDOT:PSS film with an average thickness of $550 \mathrm{~nm}$ and (b) $98 \%$ PEDOT:PSS+2\% $\mathrm{Fe}_{2} \mathrm{O}_{3}$ film with an average thickness of $420 \mathrm{~nm}$.

The electrochromic activity of the hybrid composite films (98\% PEDOT:PSS+2\% $\mathrm{Fe}_{2} \mathrm{O}_{3}$ ) was recorded in a lithiumbased ionic liquid. Figure 4a shows the chronoamperometric (CA) with voltage steps of $(-1 \mathrm{~V} / 30 \mathrm{~s})$ and $(0.3 \mathrm{~V} / 30$ s) in a three electrodes cell using ionic liquid based LiTFSI in EMITFSI as a supporting electrolyte and Satured Calomel Electrode as reference electrode (SCE). The cycling of the hybrid composite film shows good reversibility, and fast switching time in between the redox processes. Both response times are in the same order of $1 \mathrm{~s}$ in oxidation and $1 \mathrm{~s}$ in reduction. The hybrid composite films switch reversibly between a reduced blue state $(-1 \mathrm{~V})$ and an oxidized red state (+0.3 V) (Figure 4b).

The in-situ transmittance upon cycling of 98\% PEDOT:PSS+2\% $\mathrm{Fe}_{2} \mathrm{O}_{3} / \mathrm{LiTFSI}$ in EMITFSI/Pt/SCE is displayed in Figure $4 \mathbf{b}$. The reduced-blue state $(-1 \mathrm{~V})$ and the oxidized red state at $(0.3 \mathrm{~V})$ are associated with transmittance values of about $\mathrm{Tc} \approx 8 \%$ and $\mathrm{Tb} \approx 30 \%$ at $650 \mathrm{~nm}$, respectively, corresponding to a total optical transmittance modulation of $\Delta \mathrm{T} \approx 22 \%$. Such value may appear rather limited in terms of optical contrast but it should be kept in mind that the goal of those systems are the color change and their further use in displays favouring the integration of opaque films.

Nevertheless in regards of the EC community, the evaluation of the coloration efficiency remains a key criteria of merit. The coloration efficiency (CE) is defined as the change in optical density (OD) per unit charge (Q) inserted into or extracted from the EC films and can be calculated from the following formula [18]:

$\mathrm{CE}=\Delta \mathrm{OD} / \mathrm{Q}$

where $\Delta \mathrm{OD}=\log \left(\mathrm{T}_{\text {red }} / \mathrm{T}_{\mathrm{ox}}\right), \mathrm{Q}$ is the electrochemical capacity injected into the electrochromic material per unit area, $\mathrm{T}_{\text {red }}$ is the transmittance in the blue state, and $\mathrm{T}_{\mathrm{ox}}$ is the transmittance in the oxidized state, a coloration efficiency 37 $\mathrm{cm}^{2} \mathrm{C}^{-1}$ is obtained. 

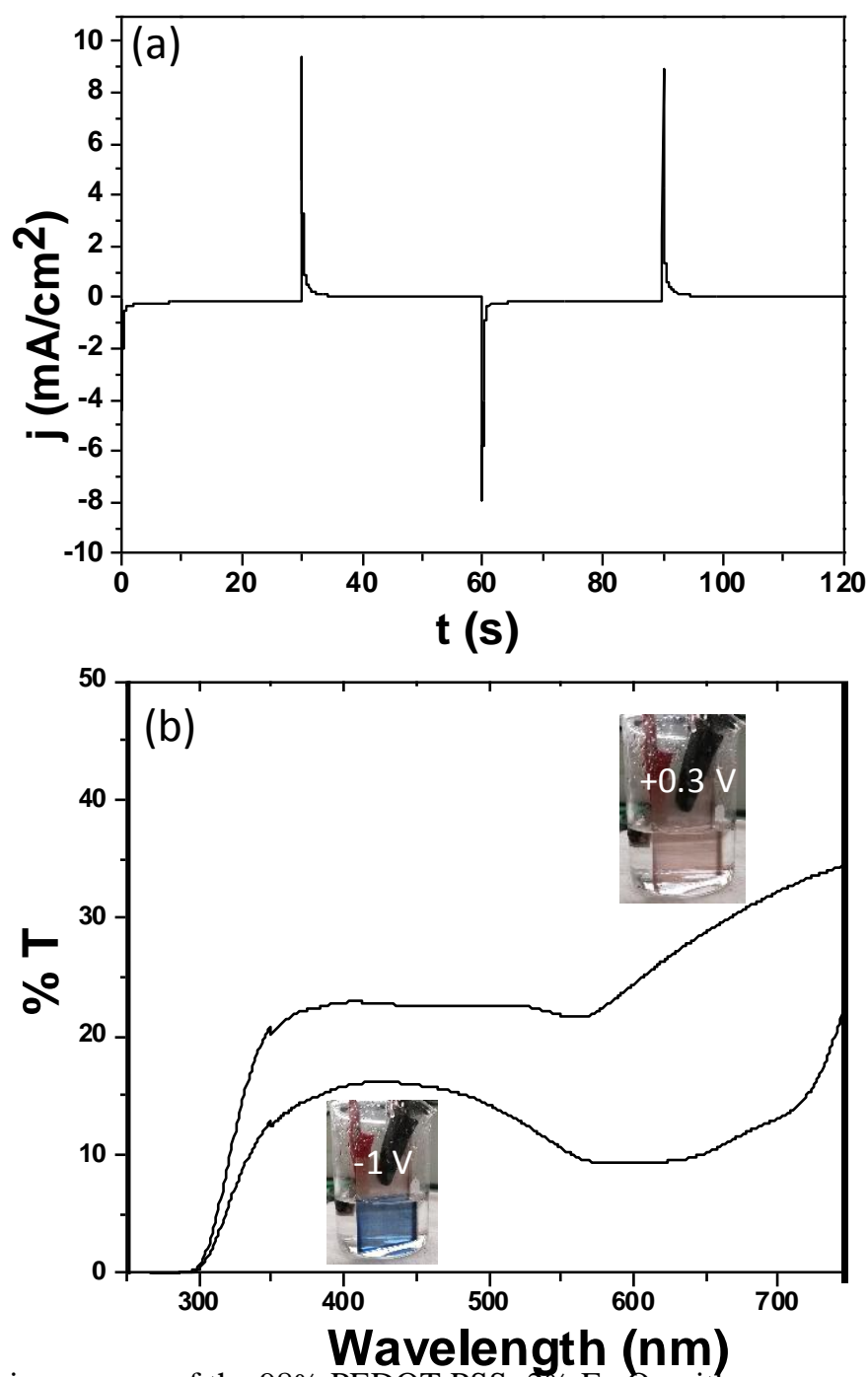

Figure 4. Electrochromic response of the 98\% PEDOT:PSS $+2 \% \mathrm{Fe}_{2} \mathrm{O}_{3}$ with an average thickness of $420 \mathrm{~nm}$. (a) Chronoamperograms cycled in 98\% PEDOT:PSS $+2 \% \mathrm{Fe}_{2} \mathrm{O}_{3} / \mathrm{Li}$-electrolyte/Pt vs SCE with voltage steps of ( -1 $\mathrm{V} / 30 \mathrm{~s})$ and $(0.3 \mathrm{~V} / 30 \mathrm{~s})$, and (b) In-situ transmittance spectra of the film cycled in $98 \%$ PEDOT:PSS $+2 \% \mathrm{Fe}_{2} \mathrm{O}_{3} / \mathrm{Li}$ electrolyte/Pt vs SCE, in reduction at $-1 \mathrm{~V}$ and re-oxidized at $0.3 \mathrm{~V}$.

\section{Conclusion}

In this paper, we have successfully elaborated and deposited hybrid composite film 98\%PEDOT-PSS $+2 \% \mathrm{Fe}_{2} \mathrm{O}_{3}$ using a bar coater with thickness ranging from 133 to $1450 \mathrm{~nm}$. The investigation of the relationship between the PEDOT:PSS/ $\mathrm{Fe}_{2} \mathrm{O}_{3}$ layer thickness and the electrochromic performances shows that the hybrid composite film with $420 \mathrm{~nm}$ exhibits superior reversible electrochromic property with nice color change between reduced blue state and oxidized red state associated with good coloration efficiency and significant transmittance modulation in lithium based electrolytes. The combination of conductive polymers and oxide/pigments is promising to address color issues in displays applications that are of interest to the scientific and industrial communities.

Acknowledgements : The activity includes in the SUPERSMART project has received funding from the European Institute of Innovation and Technology (EIT). This body of the European Union receives support from the European Union Horizon 2020 research and innovation programme. The authors wish to thank Delphin Levasseur and Thomas Rolland for helpful discussion. 


\section{References}

[1] A. Kavanagh, K. J. Fraser, R. Byrne, D. Diamond, An Electrochromic Ionic Liquid: Design, Characterization, and Performance in a Solid-State Platform. ACS Appl. Mater. Interfaces 5 (2013) $55-62$.

[2] M. D. Keersmaecker, A. W. Lang, A. M. Österholm, J. R. Reynolds. All Polymer Solution Processed Electrochromic Devices: A Future without Indium Tin Oxide? ACS Appl. Mater. Interfaces 10 (2018) 31568-31579.

[3] R. T. Wen, S. Malmgren, C. G. Granqvist, G. A. Niklasson. Degradation Dynamics for Electrochromic $\mathrm{WO}_{3}$ Films under Extended Charge Insertion and Extraction: Unveiling Physicochemical Mechanisms. ACS Appl. Mater. Interfaces 9 (2017) 12872-12877.

[4] I. Mjejri, L.M. Manceriu, M. Gaudon, A. Rougier, F. Sediri, Nano-vanadium pentoxide films for electrochromic displays. Solid State Ionics 292 (2016) 8-14.

[5] Z. Bi, X. Li, Y. Chen, X. He, X. Xu, X. Gao. Large-Scale Multifunctional Electrochromic-Energy Storage Device Based on Tungsten Trioxide Monohydrate Nanosheets and Prussian White. ACS Appl. Mater. Interfaces 9 (2017) 29872-29880.

[6] V. K. Thakur, G. Ding, J. Ma, P. S. Lee, X. Lu. Hybrid Materials and Polymer Electrolytes for Electrochromic Device Applications. Adv. Mater. 24 (2012) 4071-4096.

[7] C. Dulgerbaki, N. N. Maslakci, A. Komur, A. U.Oksuz. PEDOT/WO $\mathrm{WO}_{3}$ Hybrid Nanofiber Architectures for High Performance Electrochromic Devices. Electroanalysis 28 (2016) 1873-1879.

[8] G. Y. Karaca, E. Eren, C. Alver, U. Koc, E. Uygun, L. Oksuz, A. U. Oksuz. Plasma Modified $\mathrm{V}_{2} \mathrm{O}_{5} / \mathrm{PEDOT}$ Hybrid Based Flexible Electrochromic Devices. Electroanalysis 29 (2017) 1324-1331.

[9] A. Danine, L. Cojocaru, C. Faure, C. Olivier, T. Toupance, G. Campet, A. Rougier, Room Temperature UV treated $\mathrm{WO}_{3}$ thin films for electrochromic devices on paper substrate. Electrochim. Acta 129 (2014) 113-119.

[10] I. Mjejri,C. M. Doherty, M. Rubio-Martinez, G. L. Drisko, A. Rougier, Double-Sided Electrochromic Device Based on Metal-Organic Frameworks. ACS Appl. Mater. Interfaces 9 (2017) 39930-39934.

[11] J. Fei, K.G. Lim, G. T. R. Palmore. Polymer Composite with Three Electrochromic States. Chem. Mater. 20 (2008) 3832-3839.

[12] A. Danine, L. Manceriu, C. Faure, C. Labrugère, N. Penin, A. Delattre, G. E.P. Tourtollet, A. Rougier, Toward Simplified Electrochromic Devices Using Silver as Counter Electrode Material, ACS Appl. Mater. Interfaces (2019). DOI: 10.1021/acsami.9b12380.

[13] P. Shi, C. M. Amb, A. L. Dyer, J. R. Reynolds, Fast Switching Water Processable Electrochromic Polymers. ACS Appl. Mater. Interfaces 4 (2012) 6512-6521.

[14] R. H. Bulloch, J. A. Kerszulis, A. L. Dyer, J. R. Reynolds, Mapping the Broad CMY Subtractive Primary Color Gamut Using aDual-Active Electrochromic Device. ACS Appl. Mater. Interfaces 6 (2014) 6623-6630.

[15] C. Dulgerbaki, N. N. Maslakci, A. I. Komur, A. U. Oksuz. PEDOT/ $/ \mathrm{WO}_{3}$ Hybrid Nanofiber Architectures for High Performance Electrochromic Devices. Electroanalysis 28 (2016) 1873-1879.

[16] I. Mjejri, R. Grocassan, A. Rougier, Enhanced Coloration for Hybrid Niobium-Based Electrochromic Devices. ACS Appl. Energy Mater. 1 (2018) 4359-4366.

[17] D. Levasseur, I. Mjejri, T. Rolland, A. Rougier, Color Tuning by Oxide Addition in PEDOT:PSS-Based Electrochromic Devices. Polymers 11 (2019) 179.

[18] C. Yan, W. Kang, J. Wang, M. Cui, X. Wang, C. Foo, K. J.Chee, P. S. Lee, Stretchable and Wearable Electrochromic Devices. ACS Nano. 8 (2014) 316-322. 